\title{
Factors Affecting the Perceptions of Small-Scale Organic Farmers in South Africa: An OLS Approach
}

\author{
Gabriel Adewunmi Eyinade, ${ }^{*}$ Celestine Ohi Akharume \\ Department of Agricultural Economics and Extension, University of Fort Hare, South Africa \\ mirrorspace@gmail.com, akharumecelestine@gmail.com
}

\begin{abstract}
Much investments have been tailored towards organic farming by several stakeholders in recent years. Reasons for these are poverty mitigation, income generation as well as food security and good dietary diets. Unfortunately, there are no significant improvements in those areas where organic farming has been funded and encouraged. The study aims at identifying factors affecting the perceptions of small-scale organic farmers using ordinary least square regression model (OLS). One hundred and sixty structure questionnaires were administered on 160 small-scale organic farmers in Amathole District Municipality to gather data for the study. The results revealed that gender and educational level are the major factors affecting the perceptions of small-scale organic farmers in South Africa. Nevertheless, to open the prospective of smallscale organic farmers, the study suggested that these farmers should have greater access to extension services and support. This will go a long way in assisting the farmers to diversify and improve their production, thus enhancing livelihoods and creating markets for organic foods.
\end{abstract}

Keywords: Food security; livelihood; OLS regression model; organic farming; perception.

\section{Introduction}

The persistent of floods, recurrent droughts, land grabbing, water shortage, and soil degradation are some of the teeming challenges confronting agriculture in developing countries (Fasona \& Ogunkunle, 2018). The frequent occurrence of these factors poses a serious challenge to food security and rural livelihoods. Although, agriculture has been known to be the backbone for rural development and poverty mitigation, the twin challenges of food insecurity and environmental degradation remains a global phenomenon (Cole, Bailey, \& New, 2014). To combat these environmental challenges, organic farming is thus required. It is worth mentioning that the importance of organic farming in South Africa is to produce quality food in an environmentally friendly way, suitable for consumption with little or no effect on the environs. Surprised, this goal has not been fully actualized by the modern farming practices, (i.e. inorganic farming) which is the prominent farming activity in South Africa. Thus, it is essential to encourage the adoption of sustainable organic agriculture in the country which is proficient of providing lasting solutions to the existing agricultural difficulties and aid to attain optimum productivity of nutritional and quality food (Madhavan et al., 2012). To achieve this goal, sustainable organic agriculture is thus necessary. Under Food, Agriculture, Conservation, and Trade Act of 1990 (FACTA, Washington, DC), termed the word "sustainable agriculture" as a unified method employed in plant, and animal production practices, encompassing all successful management of agricultural goods to meet human wants, enhance the quality of life for farmers while maintaining or enhancing environmental stability of all natural resources. All definitions of sustainable agriculture lay emphasis on retaining a stable agricultural development rate, which can meet the demand for food of all living organisms without degrading the elementary resources of the environment. Organic farming has been identified as one of the several methods found to meet the goals of sustainable agriculture (Roychowdhury et al., 2013). Reasons are; organic farming prohibits the use of man-made inputs such as synthesized manure, insecticides and herbicides. The foregoing is associated with modern agricultural practices specifically the use of artificial manures and pesticides in farming. The negative effect of this is on the environs through soil erosion, soil adulteration and bioaccumulation resulting in food poison and environmental degradation (Hardy, 2014).

Organic farming is therefore one of the most suitable alternatives that can be considered as a sustainable approach for small-scale farmers in less developed countries because it offers a low combination of external inputs, technical know-how, friendly environment as well as efficient input/output utilisation (Augustine et al., 2013). Several literatures have defined organic farming in several ways; the United States Department of Agriculture (USDA), described the word organic farming as a technique that is planned and conserved to produce agricultural goods using approaches and materials that keep alive the ethics of organic agricultural goods until they get to the final consumer. Treadwel et al. (2010) defined organic farming as the active 
environmental management approaches that preserve and enrich soil micro-organism, prevent soil erosion, boost and improve bio-diversity, and lessen risk to human and animal health and natural resources. Similarly, Yadav et al. (2013) defined organic farming as a method of production which excludes, or basically prohibits the use of artificial manures, growth regulators, livestock feed additives, and pesticides. The most universally acknowledged definition of organic farming was given by Codex Alimentarius Commission (2010) "as holistic production management systems (for crops and livestock) emphasizing the use of organic management practices in preference to the use of off-farm inputs". This is achieved by using biological, cultural and mechanical techniques of controlling weeds in preference to artificial substances (Van Driesche, \& Hoddle, 2009).

Moyer (2013) highlighted that organic farming is often advanced efficiently in terms of net income and thus reduces poverty affecting smallholder farmers as well as making them more food secured. Several studies have also shown that socio-economic features of farmers could play a major role in determining farmers' perception on organic farming adoption (both technical and economic). For example, a study conducted by Kafle (2011) while investigating factors that affect the adoption of organic vegetable farming in Chitwan District of Nepal, the results reveal that farm size, farmers' involvement in organic farming related trainings and visits and compatibility of organic farming to their situations were among the factors affecting adoption of organic farming among farmers. Similarly, Pinthukas (2015) findings revealed that age, educational level, household size, labour and extension visit were among the socio-economic variables that contributed significantly to farmers' perception on organic vegetable production for sustainable livelihood in Chiang Mai Province.

According to Borges et al. (2015), perception is an act of decision to adopt an innovation. These scholars further stressed that farmers' decision to adopt an innovation is guided by variables such as farmer socioeconomic factors, farm characteristics and acquisition of information/process of learning about organic farming. The decision to adopt an innovation relies on these factors. Nonetheless, these variables influence farmers' perception towards the adoption of organic farming practices. This can be seen in South Africa, where organic farming is growing gradually and is found suitable for small-scale farmers. These farmers produce for subsistence and sell their excess produce in nearby markets. There is huge prospect in practicing organic farming because it is productive and sustainable (Herath, \& Wijekoon, 2013). This system is best suited for the rural farmers, majority of who are resource-poor. This is a practical example of the small farmers in South Africa, particularly in the Amathole District of the Eastern Cape Province. Although, very few studies have been done investigating thoroughly on small-scale organic crop farming, to the best knowledge of these researchers in Amathole District Municipality of the Eastern Cape Province. Hence, this paper intends to investigate the factors that determine perception of small-scale organic farmers in South Africa as a way to draw the awareness of the government, donors and development agencies to adequate empirical research on the adoption of organic farming and its importance for agricultural sector regarding promoting the growth of organic farming in South Africa.

\section{Methodology}

Description of the study area: The study was carried out in the Amathole District region of the Eastern Cape Province. Amathole is located between Port Alfred and Port St John's. The region extends from the Indian Ocean coastline in the South to the Amathole Mountains in the North. The region covers a land area of approximately $23,577.11 \mathrm{~km}^{2}$ and has the second largest economy in the Province, contributing to 32 percent to the provincial economy. Two-thirds of the district is made up of communal areas with high level of farming activities. The area receives rainfall throughout the year which is mainly a summer rainfall region. The mean yearly rainfall varies from $1000 \mathrm{~mm}$ along the coast to $700 \mathrm{~mm}$ inland above Butterworth and $1200 \mathrm{~mm}$ in the Amathole mountains.

Sampling procedure: Organic crop farmers constituted the population of the study. A multi-stage sampling technique was used for the study. In the first stage purposive sampling was used to select Amathole Municipality from the six District Municipalities in the Eastern Cape Province, reason is because it's well known for agricultural practices, high population of small-scale crop farmers and potential for organic crop farming (Kisaka-Lywayo \& Obi, 2014). In the second stage, simple random sampling technique was used to 
select Mdantsane, Fort Beaufort, Keiskamahook and Middle drift villages in Amathole District Municipality. These villages were randomly selected based on literature and information from extension officers. The third stage involved snow ball technique to locate the small-scale organic crop farmers through the help of extension officers from the Department of Agriculture and Agrarian reform in South Africa. A total of 160 small-scale organic crop farmers' were chosen from the four villages which made up the sample size for the study.

Data collection: This research employed primary and secondary source of data. Primary data were collected through structured questionnaires to get information on organic crop production. The questionnaires were used for those practicing organic crop farming. This was subjected to validity and reliability tests in order to avoid unbiased data collection. The secondary data was used to gather information from journals, books and articles on organic crop farmers.

Data analysis: The study adopted inferential statistics in form of Ordinary Least Square (OLS) regression model to examine the coefficients of the socio-economic variables affecting small-scale farmers' perception on organic crop farming in the study area. The collected data were coded and analysed using Statistics Package for Social Sciences (SPSS) version 24. To achieve the objective of this paper, the model intends to predict the association between two or several explanatory variables by multiple linear equations to analyse the set of data collected (Gujarati \& Porter, 2011). Several studies have used multiple regression models to examine the relationship of several independent variables on farmer's perception on organic production (Herath \& Wijekoon, 2013; Pinthukas, 2015). The functional form that gave the finest fit in terms of value of the $\mathrm{R}^{2}$ and better F-ratio was finally selected and used for the analysis. Therefore, the implicit model is:

$Y=f\left(X_{1}, X_{2}, X_{3}, X_{4}, X_{5},+U\right)$.

Where:

$\mathrm{Y}=$ Perception, which is the dependent variable, while the X's are the explanatory variables (factors influencing perception, which is the dependent variables)

$\mathrm{X}_{1}=$ household size $(\mathrm{Hs})$

$\mathrm{X}_{2}=$ gender

$\mathrm{X}_{3}=$ age

$\mathrm{X}_{4}=$ educational level

$\mathrm{X}_{5}=$ access to extension service

$\mathrm{U}=$ error of disturbance term.

\section{Results and Discussion}

Table 1: Model summary on perception

\begin{tabular}{llllllll}
\hline Model & $\mathbf{R}$ & R square & $\begin{array}{l}\text { Adjusted } \\
\text { R square }\end{array}$ & $\begin{array}{l}\text { Std. Error } \\
\text { of } \\
\text { estimate }\end{array}$ & $\begin{array}{l}\text { R square } \\
\text { change }\end{array}$ & F change & Sig \\
\hline 1 & $0.301^{\text {a }}$ & 0.090 & 0.055 & 3.355 & 0.090 & 2.534 & $0.023^{* *}$ \\
\hline
\end{tabular}

a. Predictors: (Constant), Household size, Gender, Age, Number of years in school, Access to extension service

b. Dependent Variable: Perception

Source: Results from SPSS generated from Field Survey, 2016 where Std.

Error $=$ Standard Error: According to the results summarized in Table 1, R-Square (i.e. coefficient of determination) is 0.090 . This means that as much as $9 \%$ of the variation in the perception of the small-scale farmers is explained by the explanatory variables included in the model. The remaining $91 \%$ is explained by other factors not included in the model. Adjusted R-Squared is lower than R square which shows a good model. This suggested that the Adjusted R-Squared value of 0.055 explains $55 \%$ of the variation in the dependent variable. It takes into account the number of variables entered into the model and does not necessarily increase as more variables are added. It further suggests that correction has been made to reflect 
the number of variables in the equation and estimate of variance explained and removes variability that is likely due to chance. F- Value (2.534) is significant at 5\% implying that the model is statistically significant. This means that all the independent variables together predict the perception of the small-scale organic crop farmer. This result supports the findings of Adesopeet al. (2012) who reported that only two out the nine socio-economic variables correlated significantly with the adoption of organic farming practices in River State, Nigeria.

Table 2: Test of variation in model (ANOVA)

\begin{tabular}{llllll}
\hline Model & Sum of squares & Df & Mean Square & F -value & Sig \\
\hline Regression & 171.196 & 6 & 28.533 & 2.534 & $0.023^{* *}$ \\
Residual & 1722.548 & 153 & 11.258 & & \\
Total & 1893.744 & 159 & & & \\
\hline
\end{tabular}

a. Dependent Variable: Perception

b. Predictors: (Constant), Household size, Gender, Age, Number of years in school, Access to extension service

Source: Results from SPSS generated from Field Survey, 2016 where ${ }^{* *}$ 5\% significance level. Df $=$ Degree of freedom

Table 2 showed the analysis of variance in the perception of the small-scale organic crop farmers. The significance shows variation in the extent that small-scale organic crop farmers perceived organic crop farming. F- Value gives overall adequacy and significant at 0.023 . The higher the F- Value the better the overall model of the OLS equation.

Table 3: Determinants of small-scale organic crop farmers' perception

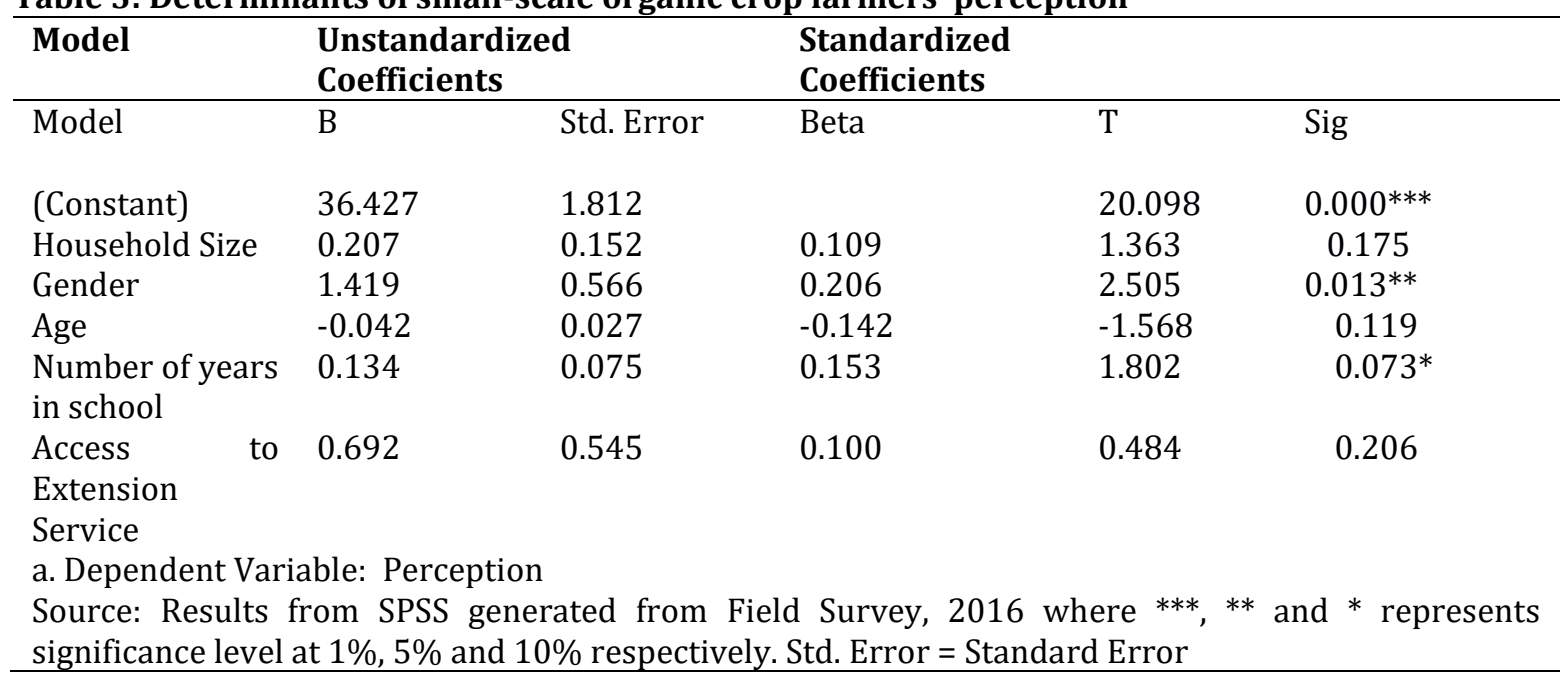

Table 3 presented the results of the estimation of the OLS model. The results suggested that perception of the small-scale organic crop farmers is significantly affected by the gender of the household head and number of years in school at 5\% and 10\% respectively. From the analysis, coefficient of gender is positive and significant at 0.013 levels suggesting that a unit change in the gender will change perception by 2.505 . This implied that gender of the households' head especially female-headed household are more likely to perceive the practice of organic crop farming as a way of enhancing their livelihood and also become food secured. This result agreed with the findings by Nhemachena \& Hassan (2007) which reported that female-headed households are more likely to adopt several approaches of organic practices than male-headed households. In addition, the research conducted by Palacios-Lopez et al. (2017) on women and agricultural productivity as cited by Doss et al. (2017) reported that women are more greatly involved in all aspects of agricultural productivity, accounting for about 40 percent of their involvement in agricultural productivity. Similarly, Doss (2014) concluded that women contributed to about $60-80 \%$ of the food that is being produced in developing 
countries. This is a clear evidence that women involvement in agricultural production is encouraging. The coefficient of number of years of schooling is positive and significant at $0.073(10 \%)$ level suggesting that for every one unit change in the number of years in school, perception will change by 1.802 . This could be interpreted that with increase in number of years in school, the farmer had greater potentials to perceive and adopts the use of modern technology. This result agreed with the findings by Gido et al. (2013) that education had a positive relationship with farmers' perception towards organic farming.

\section{Conclusion}

The study concludes that there are several factors influencing the perception of small-scale organic farmers. These factors include gender and level of education. It was found that majority of the respondents are females. Also, it was found that most of the respondents are not educated. These two variables significantly affect the perceptions of small-scale farmers practicing organic farming. Although, several factors were tested in this study using OLS, gender and level of education proved to be the dominant factors influencing farmers' perception, whether to continue adopting organic farming or quit the practice. Thus, to secure the establishment and a further growth of an organic market, it is essential to unlock the potential of small-scale organic farmers' perception to organic farming.

Recommendations: In the light of study outcomes, it is therefore recommended that there is a need for farmers' education on organic farming practices through greater access to extension services and support to help enhance their awareness and production system. This will also provide them with adequate information about global challenges and opportunities in adopting organic farming, thereby enhancing their livelihoods. There is also need for government and private sectors to collaborate on educating and enlightening smallscale farmers about the prospect of adopting organic farming as a way of attaining food security and nutritional diets, and live a life free of environmental bioaccumulation.

Acknowledgments: The authors wish to express their gratitude to the University of Fort Hare, Govan Mbeki Research and Development Centre and the Department of Agriculture and Agrarian Reform of South Africa for their support to develop this paper.

\section{References}

Adesope, O. M., Matthews-Njoku, E. C., Oguzor, N. S. \& Ugwuja, V. C. (2012). Effect of socio-economic characteristics of farmers on their adoption of organic farming practices. In Crop Production Technologies. InTech.

Augustine, A. J., Jokthan, G. E., Zarafi, I. C. \& Bivan, G. M. (2013). Optimizing opportunities for sustainable development through organic agriculture in Nigeria. Journal of Agriculture and Veterinary Science, 4 , 07-11.

Borges, J. A. R., Foletto, L. \& Xavier, V. T. (2015). An interdisciplinary framework to study farmers' decisions on adoption of innovation: Insights from Expected Utility Theory and Theory of Planned Behavior. African Journal of Agricultural Research, 10(29), 2814-2825.

Codex Alimentarius Commission, \& Codex Alimentarius Commission. (2010). Guidelines for the production, processing, labelling and marketing of organically produced foods. CAC/GL, 32-2010.

Cole, M. J., Bailey, R. M. \& New, M. G. (2014). Tracking sustainable development with a national barometer for South Africa using a downscaled "safe and just space" framework. Proceedings of the National Academy of Sciences, 111(42), E4399-E4408.

Doss, C., Meinzen-Dick, R., Quisumbing, A. \& Theis, S. (2017). Women in agriculture: Four myths. Global Food Security.

Doss, C. (2014). If women hold up half the sky, how much of the world's food do they produce? In Gender in Agriculture (pp. 69-88). Springer Netherlands.

Fasona, M. \& Ogunkunle, O. J. (2018). Some Aspects of Natural Resource Exploitation and Management in Nigeria. In Handbook of Research on Environmental Policies for Emergency Management and Public Safety (pp. 22-39). IGI Global. 
Gido, E., Lagat, J., Ithinji, G., Mutai, B., Sibiko, K. \& Mwangi, J. (2013). Maize farmers' perceptions towards Organic Soil Management Practices in Bungoma County, Kenya. Research Journal of Environmental and Earth Sciences, 5(2), 41-48.

Gujarati, D. N. \& Porter, D. C. (2011). Econometria Básica-5. AMGH Editora.

Hardy, M. C. (2014). Resistance is not futile: It shapes insecticide discovery. Insects, 5(1), 227-242.

Herath, C. S. \& Wijekoon, R. (2013). Study on the attitude and perception towards organic cultivation in organic and non-organic coconut producers. Idesia (Arica), 31(2), 5-14.

Kafle, B. (2011). Factors affecting adoption of organic vegetable farming in Chitwan District, Nepal. World Journal of Agricultural Sciences, 7(5), 604-606.

Kisaka-Lwayo, M. \& Obi, A. (2014). Analysis of production and consumption of organic products in South Africa.

Madhavan, G., Oakley, B., Green, D., Koon, D. \& Low, P. (Eds.). (2012). Practicing sustainability. Springer Science \& Business Media.

Moyer, J. (2013). Perspective on Rodale Institute's Farming Systems Trial. Crop Management, 12(1).

Nhemachena, C. \& Hassan, R. (2007). Micro-level analysis of farmer's adaption to climate change in Southern Africa. Intl Food Policy Res Inst.

Palacios-Lopez, A., Christiaensen, L. \& Kilic, T. (2017). How much of the labor in African agriculture is provided by women? Food Policy, 67, 52-63.

Pinthukas, N. (2015). Farmers' perception and adaptation in organic vegetable production for sustainable livelihood in Chiang Mai Province. Agriculture and Agricultural Science Procedia, 5, 46-51.

Roychowdhury, R., Banerjee, U., Sofkova, S. \& Tah, J. (2013). Organic farming for crop improvement and sustainable agriculture in the era of climate change. Online Journal of Biological Sciences, 13(2), 5065.

Safa, M. S. (2005). Socio-Economic factors affecting the income of small-scale agroforestry farms in hill country areas in Yemen: A comparison of OLS and WLS determinants. Small-Scale Forestry, 4(1), 117134.

Treadwell, D., Riddle, J., Barbercheck, M., Cavanaugh-Grant, D. \& Zaborski, E. (2010). What is organic farming? Unpublished manuscript, Cooperative Extension System, University of Massachusetts, Amherst, MA. Online. http://www. extension. org/article/18655.

Van Driesche, R. \& Hoddle, M. (2009). Control of pests and weeds by natural enemies: an introduction to biological control. John Wiley \& Sons.

Yadav, S. K., SubhashBabu, M. K. Yadav, K. S., Yadav, G. S. \& Suresh, P. (2013). A review of organic farming for sustainable agriculture in Northern India. International Journal of Agronomy, 2(2). 